\title{
STRONG SAHARAN DUST EVENT DETECTED AT LALINET LOA-UNAL STATION, OVER MEDELLÍN, COLOMBIA BY ACTIVE AND PASSIVE REMOTE SENSING
}

\author{
Andrés Bedoya $^{*(1)}$, Daniel Nisperuza ${ }^{(1)}$, Dairo Alegría ${ }^{(1)}$, Mauricio Múnera ${ }^{(1)}$, Juan Luis Guerrero- \\ Rascado $^{(2,3)}$, Carmen E. Zapata ${ }^{(4)}$, Jose F. Jiménez ${ }^{(4)}$, Eduardo Landulfo ${ }^{(5)}$ and Álvaro Bastidas ${ }^{(1)}$ \\ ${ }^{1}$ Lasers and Spectroscopy Group, Facultad de ciencias, Universidad Nacional de Colombia, Medellín \\ 050034, Colombia, *Email: aebedoyav@unal.edu.co \\ ${ }^{2}$ Dpt. Applied Physics, Faculty of Sciences, University of Granada, Fuentenueva s/n, 18071, Granada, \\ Spain \\ ${ }^{3}$ Andalusian Institute for Earth System Research (IISTA-CEAMA), Avda. del Mediterráneo s/n, 18006, \\ Granada, Spain \\ ${ }^{4}$ Laboratorio de Calidad del Aire (CALAIRE), Facultad de Geociencias y Medio Ambiente, Universidad \\ Nacional de Colombia, Medellín 050041, Colombia. \\ ${ }^{5}$ Centro de Lasers e Aplicações, Instituto de Pesquisas Energéticas e Nucleares (IPEN), Avd. Prof. Lineu \\ Prestes2242, 05508-000, São Paulo, Brazil 4
}

\begin{abstract}
Passive and active remote sensing techniques are well used for understanding optical and microphysical characteristics of aerosol layers. Lidar has the ability to resolve stratifications of the complex vertical structures in the atmosphere and determine the existence of aerosols which has been transported for long-ranges through the evaluation of the optical properties such as particle backscatter and extinction coefficients, among others. CIMEL sunphotometer data (AERONET network) give information about optical properties such as Aerosol Optical Depth (AOD), Single Scattering Albedo (SSA), and Angström Exponent (AE) and microphysical properties such as size distribution. The LOAUNAL lidar station as part of the LALINET (Latin American LIdar NETwork) [1], involves an elastic coaxial system operating in zenith mode used for monitoring the atmosphere at MedellínColombia $\left(6.26^{\circ} \mathrm{N}, 75.58^{\circ} \mathrm{W}, 1470 \mathrm{~m}\right.$ asl). This work presents a Saharan dust even over Medellín, Colombia, $27^{\text {th }}$ June, 2014, observed simultaneously with lidar, sun-photometer and complementary global mass transport model HYSPLIT.
\end{abstract}

\section{INTRODUCTION}

Anthropogenic and natural radiative forcing is a very important topic which has many uncertainties (e.g. mineral dust particles). The magnitude of dust emissions to the atmosphere depends on the surface wind speed and many soil-related factors such as texture, moisture and vegetation cover [2]. Mainly sources of mineral dust particles on global scale are Sahara and Gobi deserts which are located on the African continent. Their principal effect is by scattering and absorption (direct effect), and their interaction with clouds (indirect effect) [3].

Mineral dust aerosols from North Africa represent one of the largest sources of aerosols available to the atmosphere, and their generation and transport are thought to be modulated by African easterly waves. The Sahara desert as the world's most important dust source adjoins directly to the Atlantic Ocean. A major part of the Saharan mineral dust injected to the atmosphere is exported towards the northern tropical Atlantic [4$6]$.

In this paper, we report an event of dust particles advected over Medellín city in Colombia, see figure 1 , which was registered by first time in this 
region, using remote sensing instrumentation: lidar and sun-photometer.

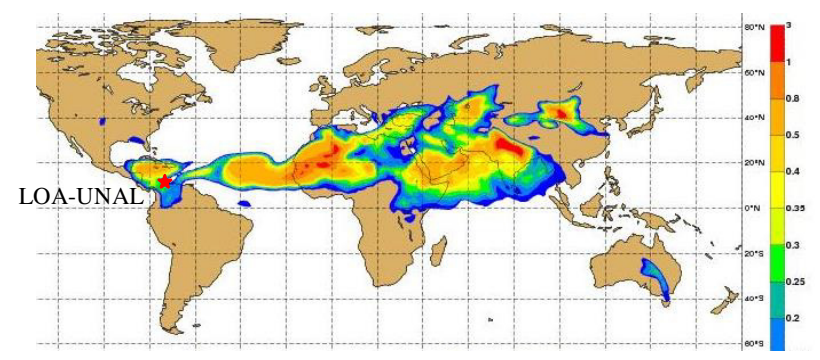

Figure 1 MACC model for representation of Dust Optical Depth transport until LALINET LOA-UNAL station.

\section{METHODOLOGY}

The available infrastructure of the LALINETLOA-UNAL station is used for monitoring the air quality, as well as in-situ (namely $\mathrm{PM}_{2.5}$ and $\mathrm{PM}_{10}$ impactors), and remote sensing (coaxial elastic lidar), operating at $532 \mathrm{~nm}$ and $355 \mathrm{~nm}$ (see figure 2), which derives aerosol optical properties trough the Klett-Fernald-Sasano algorithm [6] and the evolution of atmospheric boundary layer [7]. Also, it was used a CIMEL sun photometer of NASA-AERONET which allowing us to getting direct products (AOD and $\mathrm{AE}$, and inversion products such as particle size distribution and SSA, with uncertainties about 0.01 at wavelengths larger than $440 \mathrm{~nm}$ and about 0.02 at wavelengths shorter that this value [8].

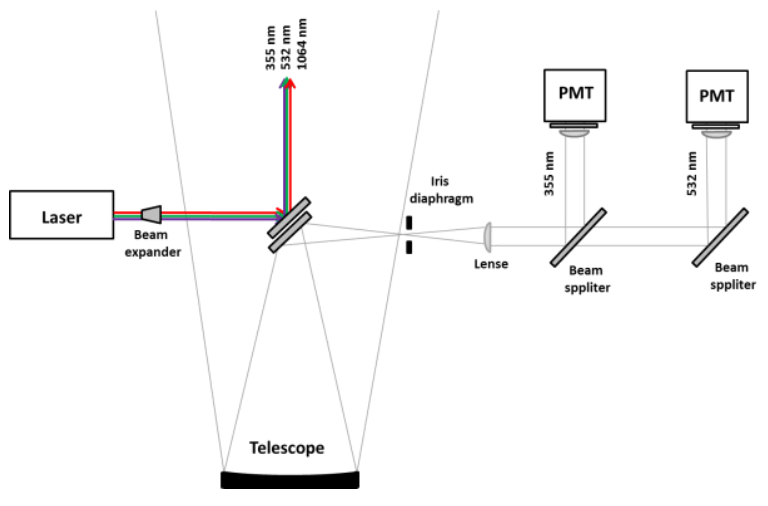

Figure 2 Lidar LOA-UNAL coonfiguration

\section{RESULTS}

The analysis of this event involved 5-day backtrajectories, calculated from HYSPLIT model, to evaluate the origin of the mineral particle advected over Medellín. The backtrajectories were computed for six altitudes (since 1000 to $6000 \mathrm{~m} \mathrm{agl}$ ) using GDAS database (Global data assimilation (System,ftp://www.arl.noaa.gov/pub/archives/gda $\mathrm{s} 1 /$ ). Figure 3 presents the backtrajectories on $27^{\text {th }}$ June 2014.

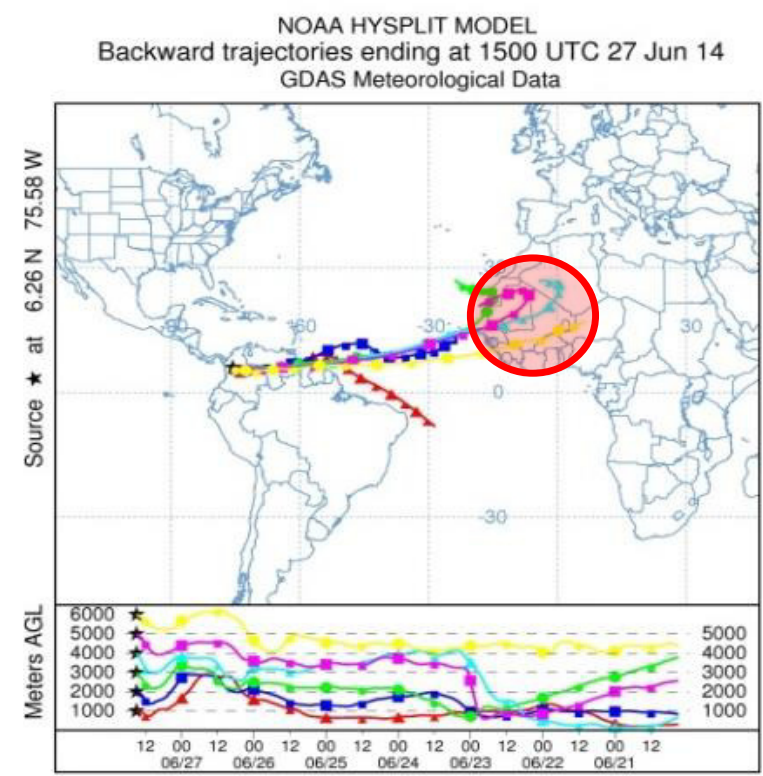

Figure 3 Hysplit 5-day backtrajectories on $27^{\text {th }}$ June 2014 ending at Medellín

The mineral particulate directly comes from the North region of Africa (Sahara desert), traveled cross the Atlantic Ocean supported by typical easterly wave. The calculated backtrajectories for this event show an injection of particles which reaches this city at medium height levels (3000$5000 \mathrm{~m} \mathrm{agl})$.

On the other hand, the event was characterized by the increasing of the optical parameters as well as $\mathrm{AOD}_{500},(0.2-0.8) \mathrm{AE}_{440-870}(0.1-0.3)$, and SSA obtained by the sun-photometer at Medellín. Also, the size distribution shows a predominance of the coarse mode over fine. [Figure 4] [9]. 

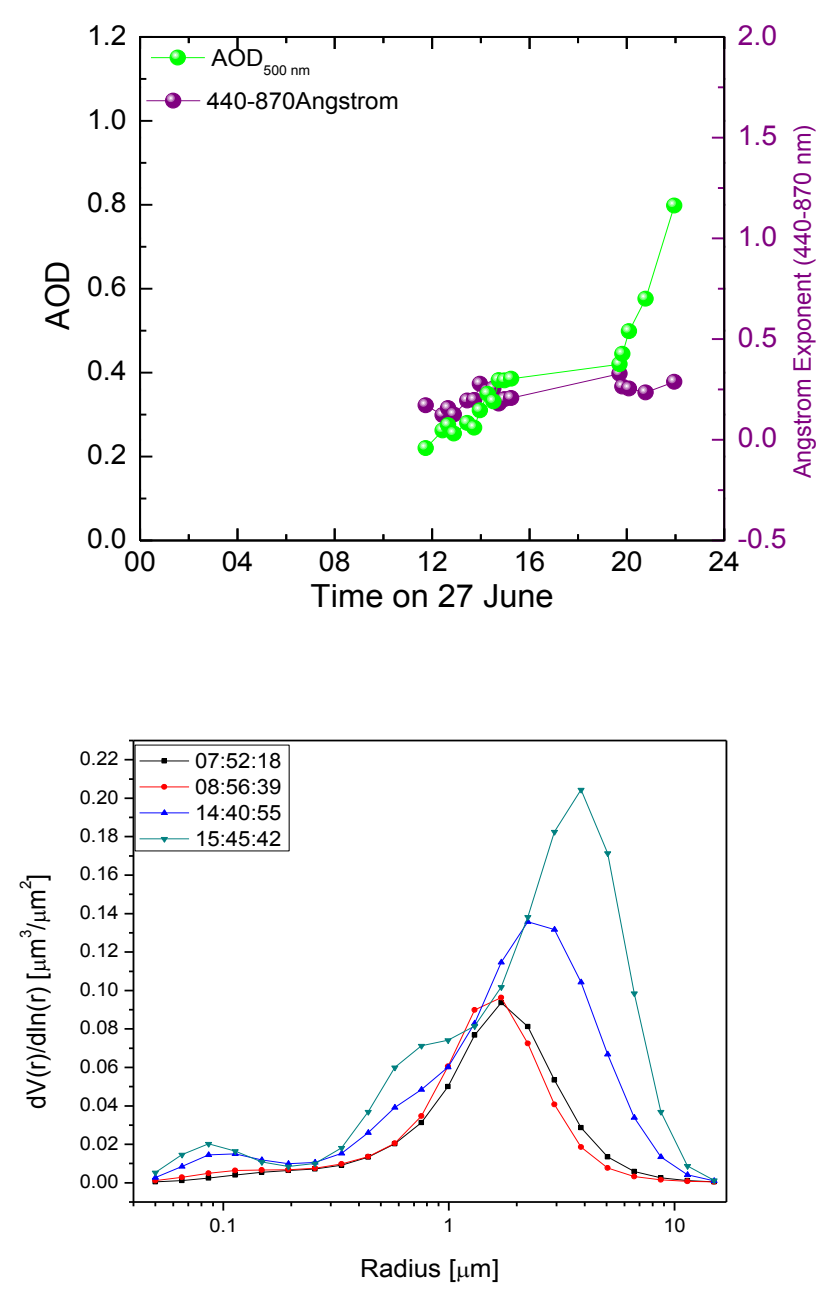

Figure 4 Sun-photometer data on $27^{\text {th }}$ June: (a) $\mathrm{AOD}_{500}$ and AE440-870 ; (b) Particle size distribution.

Above of the size distribution, the modal radius coarse $(\sim 8 \mu \mathrm{m})$, was compared with $\mathrm{PM}_{10}(140$ $\mu \mathrm{g} / \mathrm{m}^{3}$ ) data in the surface, which shown also an important increase.

In addition, lidar products were obtained through the inversion of Klett-Fernald- Sasano algorithm, in particular, the particle backscatter coefficient evolution at $532 \mathrm{~nm}$ (using a constant lidar ratio of $55 \mathrm{sr}$.) during all day, (Figure 5), involving the corresponding high accumulation.

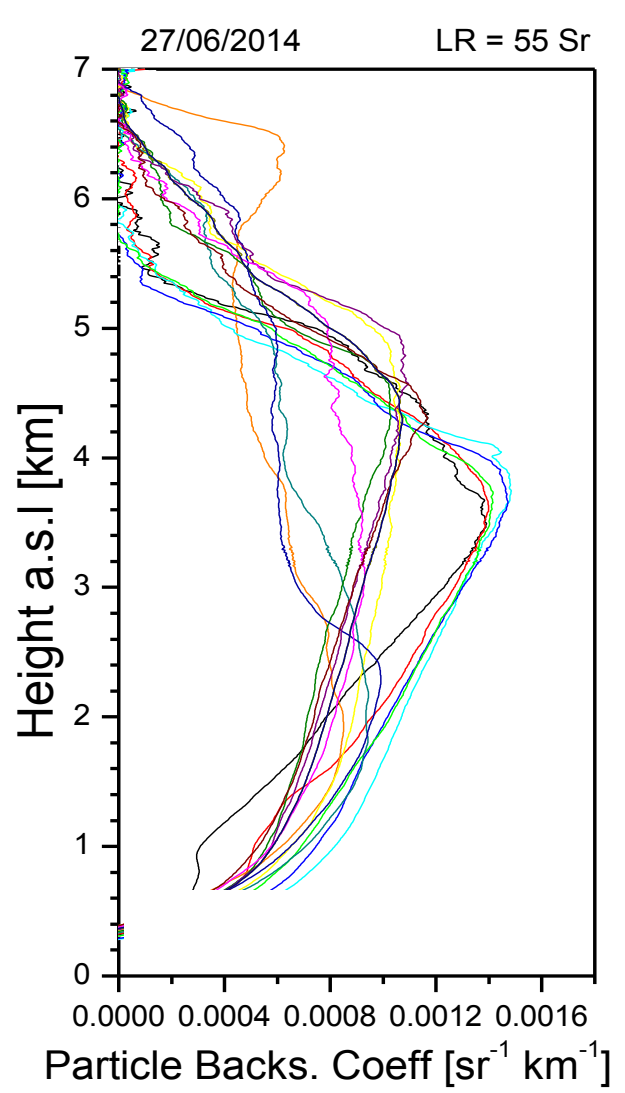

Figure 5 30-min averaged particle backscatter coefficient at $532 \mathrm{~nm}$, computed with a lidar ratio of 55 sr.

\section{CONCLUSIONS}

The methodology used in this study allowed us to characterizing for the first time a Saharan dust event over this unexplored Colombian Andean region. The synergy of passive and active remote sensing technical with the calculus of some backtrajectories air mass and in-situ measurements, were the support for obtain this results associated with Saharan dust event over Medellín, Colombia.

It was possible to see the high accumulation of particles on the backscatter coefficient, (about 3 to $5 \mathrm{~km}$ agl), during all time measurements.

This phenomenon will be studied about the local atmospheric dynamic, air quality, and its health impact. 


\section{ACKNOWLEDGEMENT}

This work has been supported by Universidad Nacional de Colombia through the LOA-UNAL station of LALINET, also by the air quality laboratory (CALAIRE) and by the University of Granada through the contract "Plan Propio. Programa 9. Convocatoria 2013". We acknowledge the use of NOAA- HYSPLIT, NAAPS and MACC models.

\section{REFERENCES}

[1] Towards an instrumental harmonization in the framework of LALINET: dataset of technical specifications, vol 9246 (924600). September 2014. Journal of applied Remote Sensing.

[2] IPCC 2013, Climate change 2013: the physical Science Basis, chapter 7

[3] Mahowald, N.M., and Kiehl, L.M. (2003). Mineral aerosol and cloud interactions. Geophysical Research Letters, 30.

[4] Wong, S. and Dessler, A.E. (2005). Suppression of deep convection over tropical North Atlantic by Saharan Air Layer. Geophysical Research Letters, 32.

[5] Middleton, N.J and Goudie, A.S. (2001). Saharan Dust: sources and trajectories, vol 26, 165-181. Royal Geographical Society.

[6] Huang, J., Zhang, C., Prospero, M.J. (2010). African outbreaks: A satellite perspective of temporal and spatial variability over the tropical Atlantic Ocean, vol 115, 1-20. Journal of Geophysical Research.
[7] Klett, J. D. (1985). Lidar inversion with stable backscattering to extinction ratios. Applied Optics, 24, 1638-1643.

[8] Nisperuza, D.J., Bedoya, A.E., Alegria, D.L., Múnera, M., Jiménez, J.F., Zapata, C.E. and Bastidas, A.E. Lidar measurements and wavelet covariance transform method to estimate the atmospheric boundary layer heights in Medellín, Colombia, Vol 47, 123-130. June 2014. Sociedad Española de Óptica (OPA).

[9] Holben, B.N., Eck, T.F., Slutsker, I., Tenré, D., Buis, J. P., Setzer, A., Vermote, E., Reagan, J. A., Kaufman, Y. J., Nakajima, T., Lavenu, F., Jankowiak, I., Smirnov, A. AERONET-A Federated Instrument Network and Data Archive for Aerosol Characterization, 1998.

[10] Dubovik, O. H. (2000). Variability of absorption and optical properties of key aerosol types observed in worldwire locations. Journal of the atmospheric sciences, 59, 590-608. 